\title{
A door-to-door survey to estimate the prevalence of Parkinsonism in Pakistan
}

\author{
This article was published in the following Dove Press journal: \\ Neuropsychiatric Disease and Treatment \\ 21 June 2016 \\ Number of times this article has been viewed
}

\section{Suliman Khan' \\ Ghulam $\mathrm{Nabi}^{2}$ \\ Muhammad $\mathrm{Naeem}^{3}$ \\ Liaqat $\mathrm{Ali}^{4}$ \\ Peter A Silburn ${ }^{1,5}$ \\ George D Mellick'}

'Clinical Neuroscience Group, Eskitis Institute for Drug Discovery, Griffith University, Nathan, QLD, Australia; ${ }^{2}$ Department of Animal Sciences, ${ }^{3}$ Department of Biotechnology, Quaid-i-Azam University, Islamabad, ${ }^{4}$ Saidu Medical College, Saidu Sharif Swat Khyber Pakhtunkhwa, Pakistan; ${ }^{5}$ The University of Queensland Centre for Clinical Research, Brisbane, QLD, Australia
Correspondence: George D Mellick Clinical Neuroscience Group, Eskitis Institute for Drug Discovery, Griffith University, 46 Don Young Road, Nathan, QLD 4III, Australia

Tel +6I 737355019

Fax +6I 737354255

Email g.mellick@griffith.edu.au
Introduction: Parkinson's disease (PD) occurs in all races and cultures, and population-related differences in frequency may provide etiological clues. The present study was designed to explore the prevalence of PD and Parkinsonism in Pakistan, the world's sixth most populous country, for which no published prevalence data are available.

Methods: We conducted a three-phase door-to-door survey in two districts of the Khyber Pakhtunkhwa province of Pakistan, to assess the prevalence of PD and Parkinsonism in a sample of 4,000 individuals aged 50 years and above.

Results: We identified 14 cases of Parkinsonism, eleven with a diagnosis of idiopathic PD. The overall prevalence estimates were 1.7/100 (95\% confidence interval [CI]: 0.9-2.46) for Parkinsonism and 1.28/100 (95\% CI: 0.6-1.94) for PD in persons aged 65 years and above. The age-standardized prevalence of PD (aged 65 years and above), normalized to the USA population in 2000 , was $1.33 / 100$, which is similar to that observed in other human populations. Of the total 14 cases, five were newly diagnosed and four had a family history of PD.

Conclusion: The estimated prevalence rates in Pakistan are similar to those observed in other human populations. The frequency of familial Parkinsonism is also equivalent to previous estimates.

Keywords: Parkinsonism, Parkinson's disease, door-to-door survey

\section{Introduction}

The reported prevalence of Parkinson's disease (PD) in different parts of the world varies considerably. Approaches such as door-to-door survey and record-based strategies have been used to estimate the prevalence of Parkinsonism in both Asian and Western populations. Some studies report lower prevalence rates in Asian populations, suggesting differences in environmental conditions and geographic or racial differences. ${ }^{1}$ Other studies report similar prevalence figures for Asian and Western populations. ${ }^{2}$ A recent community-based door-to-door survey study from Iran reported the prevalence rate of Parkinsonism closer to that of the European population. ${ }^{3}$ The probable reasons for these discrepancies are methodological differences, the use of variable diagnostic criteria, and a failure to consider differences in the age-distribution of the studied populations.

Previous literature suggested that multiphase questionnaire-based door-to-door surveys followed by examination of the suspected cases by a neurologist is a costeffective method to estimate the prevalence of $\mathrm{PD}$ and can have a high rate of detection of previously undiagnosed cases. In previous door-to-door survey studies, the proportion of previously undiagnosed cases identified ranged from $24 \%$ to $48 \%$. $^{2,4}$

Consanguineous marriages are still common in developing countries, which may pose serious health implications. Highly consanguineous populations, such as the Pakistani population, may exhibit nearly twice the risk of inherited disorders (autosomal recessive) 
compared to outbred populations. ${ }^{5}$ Compared to developing countries such as India and People's Republic of China, there is no available information of the prevalence of PD or Parkinsonism from Pakistan. Approximately 65\% of Pakistan's population resides in rural areas ${ }^{6}$ with limited access to large hospitals, which are mainly located in major cities. Furthermore, there is also a lack of hospital-based registers to track patients' records.

In the present study, we report on the results of a threephase door-to-door survey to assess the prevalence of idiopathic Parkinson's disease (iPD) and Parkinsonism in two rural districts of the Khyber Pakhtunkhwa (KPK) province of Pakistan.

\section{Methods}

\section{Study population}

The study was carried out in the KPK province of Pakistan. The total area of the province is $74,521 \mathrm{~km}^{2}$ and its projected 2011 population was 25,697,000. Lower Dir and Malakand are two of the 25 districts situated in the northern region of the KPK province, with a projected population of 1,124,000 and 703,000 , respectively. Almost $90 \%$ of the populations of both the districts live in rural areas. ${ }^{7}$

\section{Ethical approval}

Approval for this study was granted by the Institutional Research and Ethics Board of the Lady Reading Hospital (reference number 05/IREB/PGMI/LRH), Quaid-i-Azam University, and Griffith University (ESK/01/15/HREC).

\section{Screening instrument}

A standard questionnaire that sensitively assesses the presence of the symptoms of Parkinsonism, based on the previously published screening questionnaire developed by Rocca et $\mathrm{al}^{8}$ was used for the current study. The instrument consisted of 13 questions, which were translated into the national language (Urdu) (Supplementary material). The screening instrument consisted of 12 questions specific to Parkinsonism (Figure 1). Any participant with two positive answers to questions pertaining to resting tremor, bradykinesia, rigidity, and postural instability ${ }^{9}$ or with $\geq 6$ positive answers to questions in the screening instrument were considered to be eligible for physical examination. Due to low schooling in the target population, one question about small handwriting present in the original questionnaire was excluded from the instrument.

\section{Study design}

The study consisted of three phases. A total of 4,000 individuals aged 50 years and above were interviewed from both districts.

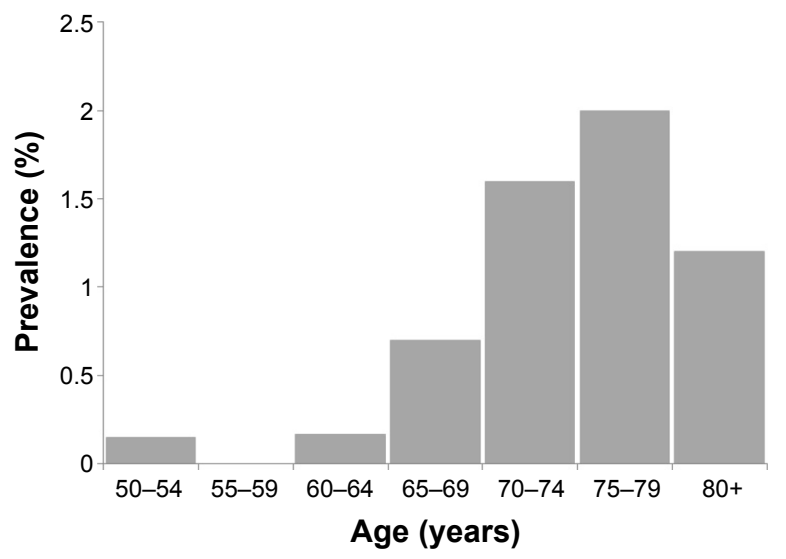

Figure I The age-specific prevalence of iPD in Pakistan as assessed by our doorto-door survey.

Abbreviation: iPD, idiopathic Parkinson's disease.

\section{Phase I}

In Phase I, conducted between September 2012 and November 2013, interviewers randomly selected houses and people within the region. Participants provided verbal consent to take part in the study. Information related to the address and date of birth was taken from participants' national identity card. For respondents who were unable to read, the interviewers asked the questions from the screening instrument. Individuals were deemed positive in Phase I on the basis of the criteria defined in the "Screening instrument" section.

\section{Phases II and III}

Individuals who screened positive in Phase I were contacted by telephone to arrange a follow-up clinical examination by a trained medical physician. Subjects were asked to bring to the examination any current or previous medical information or prescriptions. The presence of symptoms of Parkinsonism was assessed by clinical examination supported by available previous medical data; this excluded subjects with a formal diagnosis or prescription for conditions other than Parkinsonism that could explain the positive answers to the screening questions. In Phase III, individuals suspected of having signs of Parkinsonism were referred to a specialist neurologist for further detailed examination and diagnosis. The neurologist also took a family history to assess for the presence of additional family members with Parkinsonism (known as "Guzan" in the local language). Families with two or more affected members were considered positive for family history.

\section{Questionnaire validation}

The screening questionnaire was validated on 26 hospitalbased patients with neurologist-diagnosed PD and 29 randomly selected neurologically normal individuals. The study was conducted at the Lady Reading Hospital, 
Peshawar, KPK province. PD patients were recruited from the outpatient department and the Neurology ward for the validation of the screening questionnaire.

\section{Statistical analysis}

Crude and age-specific prevalence rates were estimated by dividing the number of Parkinsonism cases by the total number of screened individuals. The age-specific prevalence rate was calculated across different age groups with $95 \%$ confidence interval (CI). Age-standardized prevalence was calculated by normalizing the data to the standardized USA population in 2000. Extrapolated prevalence for nonrespondents was estimated using Ogura's method, which assumes that persons who screened positive but did not go to the clinic have a similar prevalence as the individuals who did go to the clinic..$^{10,11}$ The formula is shown below:

$$
P=\frac{\mathrm{N}}{\mathrm{A} \times(\mathrm{C} / \mathrm{B}) \times \mathrm{S}}
$$

where $\mathrm{A}$ is the number of individuals by age and sex, $\mathrm{B}$ is the number of individuals with positive screening, $\mathrm{C}$ is the number of individuals evaluated in a phase, $\mathrm{N}$ is the number of individuals affected, and $\mathrm{S}$ is the sensitivity (Table 1).

Prevalence ratios were reported per 100. Independent samples $t$-test or chi-square test, and one way Analysis of Variance (ANOVA) were used to analyze the differences between responders and nonresponders with respect to age, location, and sex.

\section{Results}

\section{Phase I}

In the first phase of the survey, a total of 4,000 individuals were approached to participate; 285 individuals refused. The overall participation rate in Phase I was 92.8\%. The participation rates in Lower Dir and Malakand districts were 90\% and $95 \%$, respectively. The mean age of the participants was 61.6 years (standard deviation [SD]: 9.7 years), with a range of 50-97 years. Furthermore, $61.5 \%$ of the participants were male $(2,288$ of 3,715$)$, with mean age of 62.2 years (SD: 9.8 years). The mean age of the female participants was 60.6 years (SD: 9.6 years). Complete demographic characteristics are summarized in Table 1 . Of the 3,715 people who completed the screening questionnaire, 303 (8.2\%) screened positive for the selected diagnostic criteria.

\section{Phases II and III}

Of the 303 participants identified in Phase I, 205 (68\%) were clinically examined; 98 (32\%) refused or were unavailable for clinical examination. The total response rate in Phase II was 68\%. The mean age and sex distribution was not significantly different between respondents and nonrespondents (Table 2). Of the 205 positive individuals, a total of 14 patients were identified with symptoms of Parkinsonism, which were further confirmed in Phase III by a trained neurologist (Table 1). Among the 14 cases, eleven comprised iPD and three cases were identified as exhibiting Parkinsonism (two atypical Parkinsonism and one drug-induced Parkinsonism). Nine of these cases had been previously diagnosed by a neurologist; five individuals were newly diagnosed. Besides iPD and Parkinsonism, other disorders such as self reported tremor, stroke, and epilepsy were also reported by the respondents (Figure 2).

\section{Prevalence}

Table 1 summarizes the prevalence data. The crude prevalence of all types of Parkinsonism for ages 50 years and above was $0.55 / 100$ (95\% CI: 0.3-0.8) and that for ages 65 years and above was 1.7/100 (95\% CI: 0.9-2.46). The crude prevalence of iPD for ages 50 years and above was $0.43 / 100$ (95\% CI: $0.22-0.64)$, and for ages 65 years and above, it was 1.28/100 (95\% CI: 0.6-1.94). For both Parkinsonism and iPD, prevalence figures were similar for men and women.

The prevalence figure of iPD in people aged 50 years and above was $0.53 / 100$ (95\% CI: $0.27-0.84)$ for males and 0.3/100 (95\% CI: 0.11-0.72) for females, while for participants aged 65 years and above, the data were $1.31 \%(95 \%$ CI: $0.6-2.3)$ and $1.21 \%$ (95\% CI: 0.44-2.70) for males and females, respectively (Table 3 ). After standardization to the USA population in 2000, the prevalence of iPD for ages 50 years and above was $0.66 / 100$ (95\% CI: 0.4-0.9); for ages 65 years and above, it was 1.33/100 (95\% CI: 0.7-2.1). Prevalence of both Parkinsonism and iPD was not significantly different between the two districts. Age-specific prevalence ratios are described in Table 1. The highest prevalence rate was found in the age group 75-79 years, which was 2.0/100 (95\% CI: 0-3.9). In the age group of 80 years and above, the rate was 1.2/100 (95\% CI: 0-2.4). A total of four cases were identified with positive family history.

\section{Questionnaire validation}

Our screening instrument showed 100\% sensitivity and 96.6\% specificity using Phase I criteria. Two questions in the first part of the screening tool (arising from chair and poor balance) demonstrated a low degree of specificity (Figure 3). The remaining questions demonstrated excellent specificity. 


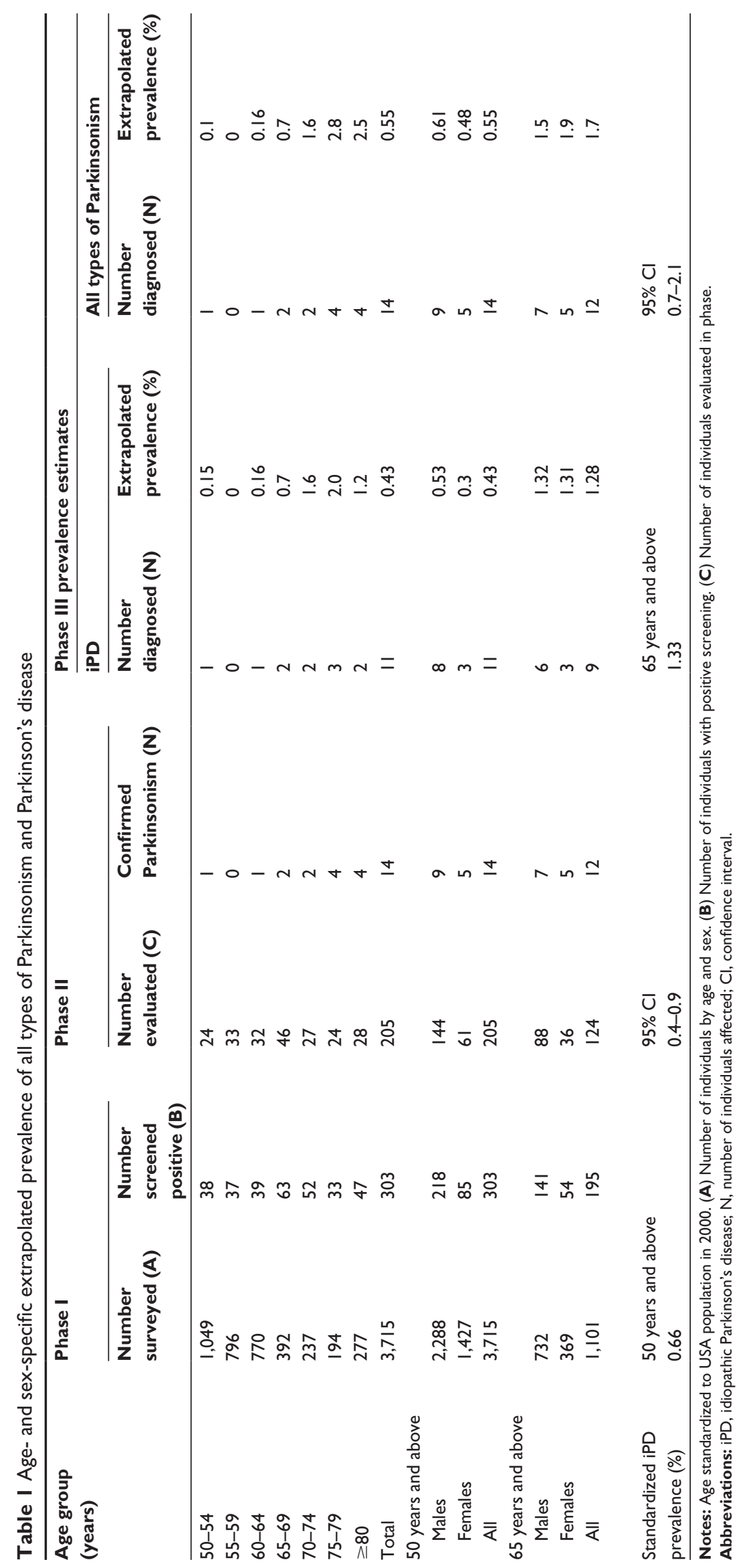


Table 2 Number of respondents and nonrespondents in Phase II

\begin{tabular}{llllll}
\hline Phase II & Number of respondents & Number of nonrespondents & N & P-value & Mean age (years) \\
\hline \multicolumn{1}{l}{ Sex } & & & & & \\
$\quad$ Males & 144 & 74 & 218 & 0.3 & 68.1 \\
$\quad$ Females & 61 & 24 & 85 & - & 66.8 \\
Location & 112 & 53 & 165 & 0.9 & 66.2 \\
$\quad$ Lower Dir & 93 & 45 & 138 & - & 69.5 \\
$\quad$ Malakand & 67 & 69 & & 0.1 & 67.7 \\
Mean age (years) & & & & \\
\hline
\end{tabular}

Abbreviation: $\mathrm{N}$, number of individuals.

\section{Discussion}

This study used a door-to-door survey method to estimate the prevalence of Parkinsonism in provincial Pakistan. This approach had advantages relative to a record-based study design, which may underestimate the prevalence of PD, especially in countries with limited access to centers treating movement disorders. Record-based studies from Asian countries have reported prevalence rates of $0.35-0.68$ per $100 .^{12,13}$ Ratios estimated through the doorto-door methods are generally higher (0.51-1.76 per 100 for all ages), ${ }^{2,14}$ although one isolated study by Wang et al ${ }^{15}$ is an exception to this trend.

Our Phase I participation rate (92\%) is similar to that obtained in other door-to-door surveys. ${ }^{16} \mathrm{~A}$ somewhat lower response rate of $68 \%$ was observed in Phase II, although no significant differences were observed between the respondents and nonrespondents in terms of age and sex. The Phase II response rate of a three-phase door-to-door survey conducted in Bidasoa, Spain, was 78.5\%, ${ }^{11}$ which is relatively similar to our Phase II response rate. In Asia, most of the door-to-door surveys have been conducted in People's Republic of China. A large-scale cross-sectional study ${ }^{2}$ performed in the Chinese population reported a prevalence rate of 1.7/100 in individuals aged 65 years and above, which is close to our estimated rate of $1.23 / 100$.

Our estimated prevalence figure is also similar to that in door-to-door surveys conducted in European countries. A large collaborative door-to-door study ${ }^{16}$ conducted in different European countries (EUROPARKINSON) reported a prevalence rate for $\mathrm{PD}$ of $1.6 / 100$, which is close to the PD rate of $1.23 / 100$ found in our study. It is generally accepted that the incidence of PD is higher in men. Several studies observe a higher prevalence of PD in men, ${ }^{17}$ while others report no difference. ${ }^{16}$ In our study, we observed similar rates of Parkinsonism and iPD in men and women. Our result is similar to that reported in the Chinese population. ${ }^{2}$
A screening instrument with high sensitivity and specificity can be a good tool for early detection of the symptoms of Parkinsonism. Our screening questionnaire had high sensitivity (100\%) and specificity (96.2\%) in hospital-based samples of patients and controls. A similar sensitivity and specificity was reported by Duarte et $\mathrm{al}^{18}$ using a nine-item screening instrument in 50 hospital-based PD patients and 100 ophthalmological patients.

In the present study, we identified five individuals with PD. None of these people had a previous diagnosis of the disease. This rate of previously undiagnosed PD cases is similar to that obtained in earlier door-to-door studies. ${ }^{2,4}$ PD is more frequent in older populations. A similar trend of increasing prevalence with age was found in our study. A peak prevalence rate was observed at the age of 75-79 years, followed by a decrease at 80 years and above (Figure S1). Similar relationships between prevalence and age are reported elsewhere. ${ }^{19}$ It has been speculated that the observed drop-off at very old ages is in part due to the reduced sample size in this tier of the population and the reduced participation rate of very elderly members of the society. It has also been suggested that common conditions, such

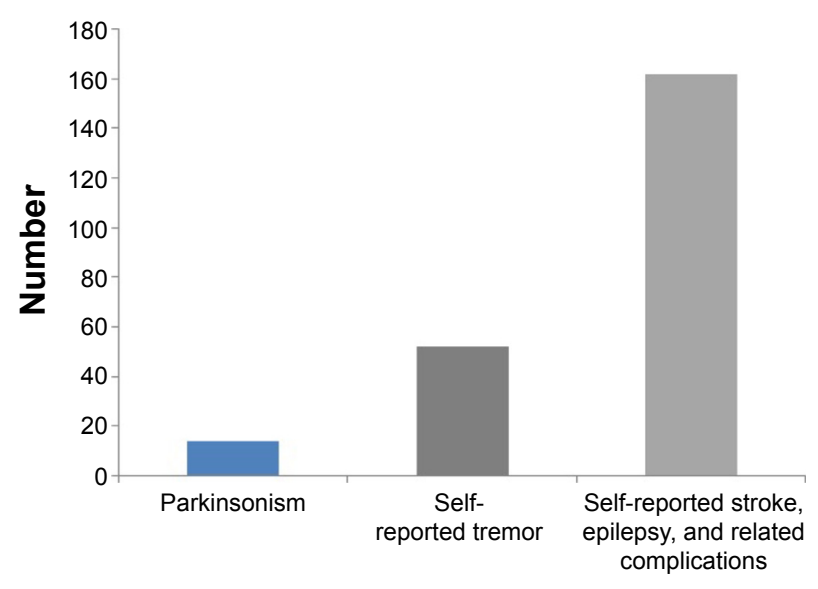

Figure 2 Parkinsonism and self-reported non-Parkinsonism complications. 
Table 3 Number of cases identified by age, sex, and location of all types of Parkinsonism and iPD in Phase III

\begin{tabular}{|c|c|c|c|c|c|c|}
\hline \multirow[t]{2}{*}{ Age group } & \multicolumn{3}{|c|}{ All types of Parkinsonism } & \multicolumn{3}{|c|}{ iPD } \\
\hline & $\mathbf{N}$ & $\begin{array}{l}\text { Extrapolated } \\
\text { prevalence (\%) }\end{array}$ & $95 \% \mathrm{Cl}$ & $\mathbf{N}$ & $\begin{array}{l}\text { Extrapolated } \\
\text { prevalence (\%) }\end{array}$ & $95 \% \mathrm{Cl}$ \\
\hline \multicolumn{7}{|c|}{50 years and above } \\
\hline Male & 9 & 0.61 & $0.28-0.92$ & 8 & 0.53 & $0.27-0.84$ \\
\hline Female & 5 & 0.48 & $0.12-0.84$ & 3 & 0.3 & $0.11-0.72$ \\
\hline Total & 14 & 0.55 & $0.3-0.8$ & 11 & 0.43 & $0.22-0.64$ \\
\hline \multicolumn{7}{|c|}{65 years and above } \\
\hline Male & 7 & 1.5 & $0.6-2.3$ & 6 & 1.32 & $0.6-2.3$ \\
\hline Female & 5 & 2 & $0.5-3.4$ & 3 & 1.21 & $0.4-2.7$ \\
\hline Total & 12 & 1.7 & $0.9-2.46$ & 9 & 1.28 & $0.6-1.94$ \\
\hline \multicolumn{7}{|l|}{ Location } \\
\hline Lower Dir & 6 & 1.65 & $0.57-2.7$ & 4 & 1.12 & $0.22-1.98$ \\
\hline Malakand & 6 & 1.73 & $0.65-2.8$ & 5 & $\mathrm{I} .45$ & $0.46-2.44$ \\
\hline
\end{tabular}

Abbreviations: $\mathrm{Cl}$, confidence interval; iPD, idiopathic Parkinson's disease; N, number of cases.

as osteoarthritis, stroke, peripheral neuropathy, or dementia, in older individuals may confound the assessment of Parkinsonism. ${ }^{20}$

High consanguinity may lead to increased risk of segregating inherited disorders. Consanguineous marriages are commonly practiced in Pakistan. It is estimated that the prevalence of consanguineous marriages in Pakistan is almost $60 \%$, with $80 \%$ between first cousins. ${ }^{21}$ We were therefore interested to know whether the frequency of familial Parkinsonism was different in our target population relative to other studies worldwide. In our surveyed samples, we identified four cases with a positive family history. This is similar to the ratio $(10 \%-25 \%)$ reported in the literature ${ }^{22}$ and does not support the idea that there is an obvious increased prevalence of familial Parkinsonism in this group.

\section{Limitations of study}

The main limitation of this study is the low response rate in Phase II, which may generate uncertainty in estimating the prevalence ratio. However, the issue was resolved by calculating the extrapolated prevalence ratio, as there was no significant difference between responders and nonresponders.

\section{Conclusion}

In conclusion, we identified a prevalence of Parkinsonism and iPD in different regions of Pakistan similar to that reported in other parts of the world. A significant number of individuals with PD were newly diagnosed as part of the study. The ratio of familial PD was similar to those previously reported.

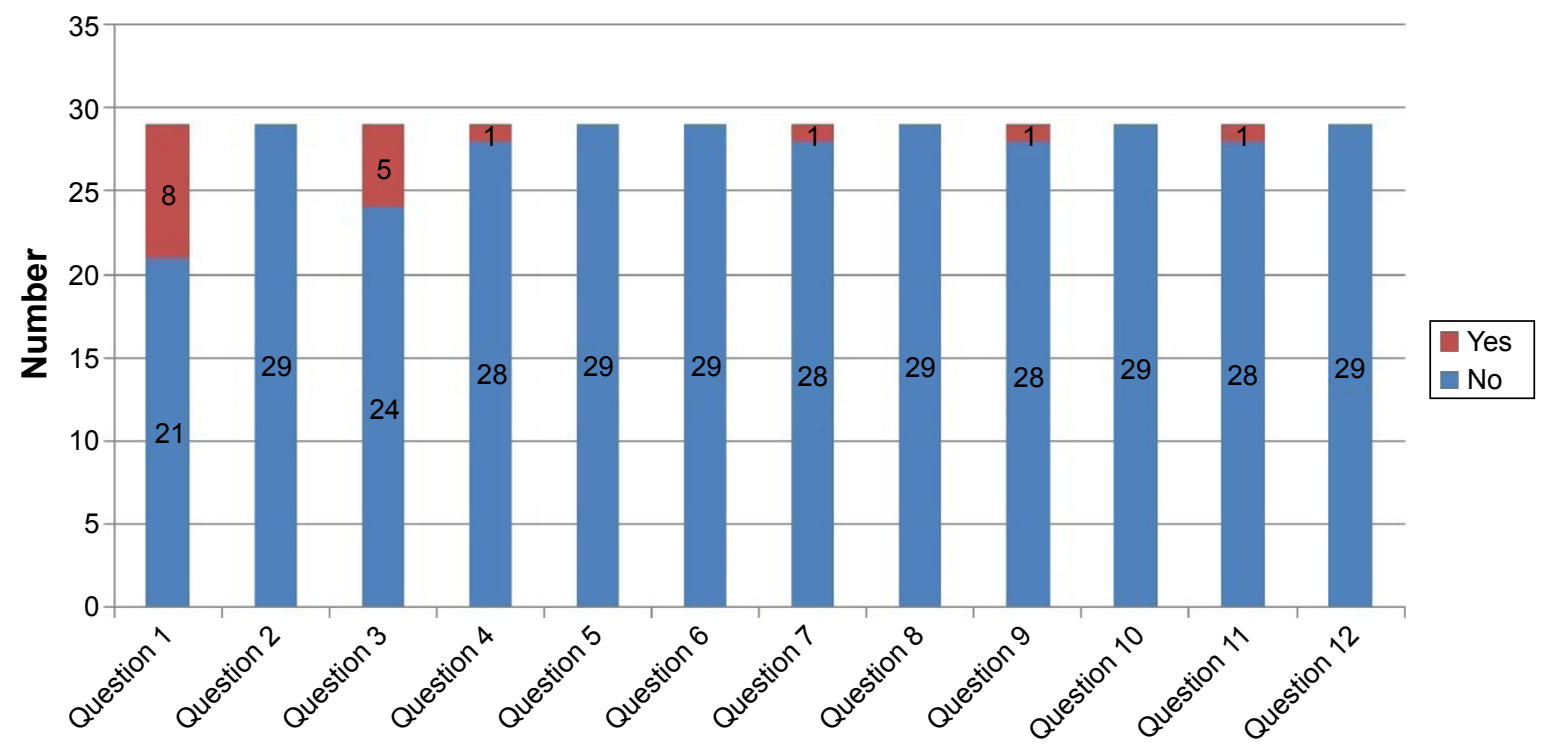

Figure 3 Hospital-based healthy individuals' responses to each question in the screening instrument. 


\section{Acknowledgments}

The authors thank the subjects for their participation. We thank Dr Rasif Salam for helping in diagnosing patients in Phase II, Professor Dr Intikhab Alam and Professor Dr Adnan Khan, Lady Reading Hospital, Peshawar, Pakistan, for assisting with questionnaire validation, and Mr Tariq Aziz for help with data collection.

\section{Disclosure}

Suliman Khan is supported by an Australian Postgraduate Award and Griffith University Postgraduate Research Scholarship. The authors report no other conflicts of interest in this work.

\section{References}

1. Pringsheim T, Jette N, Frolkis A, Steeves TD. The prevalence of Parkinson's disease: a systematic review and meta-analysis. Mov Disord. 2014;29(13):1583-1590.

2. Zhang ZX, Roman GC, Hong Z, et al. Parkinson's disease in China: prevalence in Beijing, Xian, and Shanghai. Lancet. 2005;3(9459): 595-597.

3. Fereshtehnejad S, Shafieesabet M, Rahmani A, Delbari A, Lokk J. Medium-to-high prevalence of screening-detected Parkinsonism in the urban area of Tehran, Iran: data from a community-based door-to-door study. Neuropsychiatr Dis Treat. 2015;11:321-332.

4. Benito-Leon J, Bermejo-Pareja F, Rodriguez J, Molina J, Gabriel R, Morales J. Prevalence of PD and other types of Parkinsonism in three elderly populations of central Spain. Mov Disord. 2003;18(3): 267-274.

5. Hoodfar E, Teebi A. Genetic referrals of Middle Eastern origin in a western city: inbreeding and disease profile. J Med Genet. 1996;33(3): 212-215.

6. National Institute of Population Studies (NIPS). Pakistan Demographic and Health Survey 2006-2007. Islamabad, Pakistan: Pakistan and Macro International Inc; 2008.

7. Bureau of Statistic, Government of Khyber Pakhtunkhwa, Demographic Data 2014. Government of Khyber Pakhtunkhwa Pakistan Report; 2014:267-271. Available from: http://kpbos.gov.pk/

8. Rocca WA, Maraganore DM, McDonnell SK, Schaid DJ. Validation of a telephone questionnaire for Parkinson's disease. J Clin Epidemiol. 1998; 51(6):517-523.
9. Melcon MO, Anderson DW, Vergara RH, Rocca WA. Prevalence of Parkinson's disease in Junin, Buenos Aires Province, Argentina. Mov Disord. 1997;12(2):197-205.

10. Ogura C, Nakamoto H, Uema T, Yamamoto K, Yonemori T, Yoshimura T. Prevalence of senile dementia in Okinawa, Japan. Int J Epidemiol. 1995;24(2):373-380.

11. Bergareche A, De La Puente E, López de Munain A, et al. Prevalence of Parkinson's disease and other types of Parkinsonism. A door-to-door survey in Bidasoa, Spain. J Neurol. 2004;251(3):340-345.

12. Kimura H, Kurimura M, Wada M, et al. Female preponderance of Parkinson's disease in Japan. Neuroepidemiology. 2002;21(6):292-296.

13. Harada H, Nishikawa S, Takahashi K. Epidemiology of Parkinson's disease in a Japanese city. Arch Neurol. 1983;40(3):151-154.

14. Li SC, Schoenberg BS, Wang CC, et al. A prevalence survey of Parkinson's disease and other movement disorders in the People's Republic of China. Arch Neurol. 1985;42(7):655-657.

15. Wang YS, Shi YM, Wu ZY, He YX, Zhang BZ. Parkinson's disease in China. Coordinational group of neuroepidemiology, PLA. Chin Med J (Engl). 1991;104(11):960-964.

16. de Rijk MC, Tzourio C, Breteler MM, et al. Prevalence of Parkinsonism and Parkinson's disease in Europe: the EUROPARKINSON collaborative study. European community concerted action on the epidemiology of Parkinson's disease. J Neurol Neurosurg Psychiatry. 1997;62(1):10-15.

17. Hofman A, Collette H, Bartelds A. Incidence and risk factors of Parkinson's disease in the Netherlands. Neuroepidemiology. 1989;8(6): 296-299.

18. Duarte J, Claveria L, De Pedro-Cuesta J, Sempere A, Coria F, Calne D. Screening Parkinson's disease: a validated questionnaire of high specificity and sensitivity. Mov Disord. 1995;10(5):643-649.

19. Kis B, Schrag A, Ben-Shlomo Y, et al. Novel three-stage ascertainment method prevalence of PD and Parkinsonism in South Tyrol, Italy. Neurology. 2002;58(12):1820-1825.

20. Bower J, Maraganore D, McDonnell S, Rocca W. Influence of strict, intermediate, and broad diagnostic criteria on the age- and sex-specific incidence of Parkinson's disease. Mov Disord. 2000;15(5):819-825.

21. Hussain R, Bittles A. The prevalence and demographic characteristics of consanguineous marriages in Pakistan. J Biosoc Sci. 1998;30(02): 261-275.

22. Sellbach AN, Boyle RS, Silburn PA, Mellick GD. Parkinson's disease and family history. Parkinsonism Relat Disord. 2006;12(7):399-409. 


\section{Supplementary material}

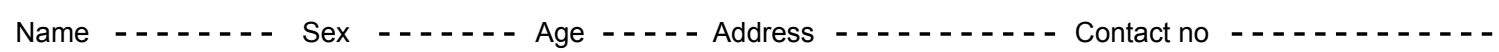

\section{Part A}

1. Do you have trouble arising from chair?

Yes No

2. Do people tell you, or have you noticed that your voice is softer than it once was?

Yes No

3. Is your balance poor?

Yes No

4. Do your feet ever seem to get stock on the floor?

Yes No

5. Do people tell you, or have you noticed that your face seems less expressive than once before?

Yes No

6. Do you have trouble buttoning buttons?

Yes No

\section{Part B}

7. Do your arms or legs shake (tremor)?

Yes No

8. Do you have a tremor when at rest or sitting quietly?

Yes No

9. Do you have a shuffling gait or are your steps short and tiny?

Yes No

10. Do you have a stooped posture?

Yes No

11. Do you notice that your arms do not swing when you walk?

Yes No

12. Do you have muscular rigidity or do you notice that you do things stiffly or slowly?

Yes No

\section{English version}

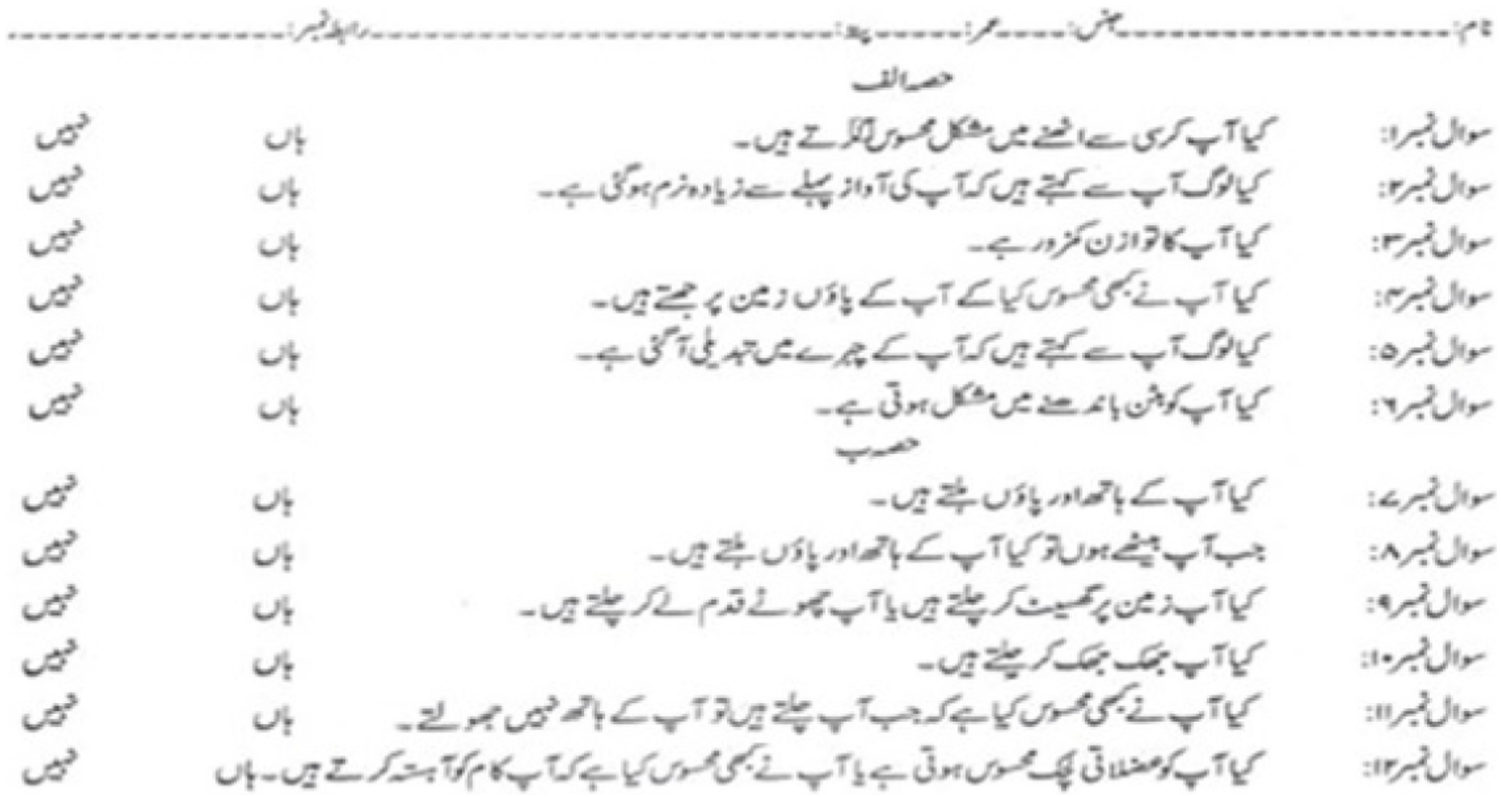

\section{Translated (Urdu) version}

Figure SI English and Urdu versions of the 12-item screening instrument questionnaire.

Neuropsychiatric Disease and Treatment

Dovepress

\section{Publish your work in this journal}

Neuropsychiatric Disease and Treatment is an international, peerreviewed journal of clinical therapeutics and pharmacology focusing on concise rapid reporting of clinical or pre-clinical studies on a range of neuropsychiatric and neurological disorders. This journal is indexed on PubMed Central, the 'PsycINFO' database and CAS,

and is the official journal of The International Neuropsychiatric Association (INA). The manuscript management system is completely online and includes a very quick and fair peer-review system, which is all easy to use. Visit http://www.dovepress.com/testimonials.php to read real quotes from published authors. 